NASA Technical Memorandum 105800

AIAA-92-3068

\title{
Three-Dimensional Navier-Stokes Heat Transfer Predictions for Turbine Blade Rows
}

Robert J. Boyle

Lewis Research Center

Cleveland, Ohio

and

Paul W. Giel

Sverdrup Technology, Inc.

Lewis Research Center Group

Brook Park, Ohio

Prepared for the

28th Joint Propulsion Conference and Exhibit

cosponsored by the AIAA, SAE, ASME, and ASEE

Nashville, Tennessee, July 6-8, 1992

\section{N/SA}

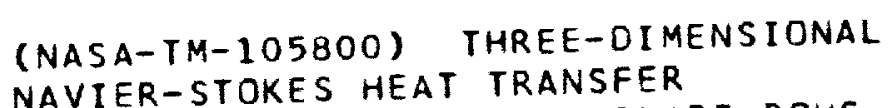
NAVIER-STOKES HEAT TRANSFER PREDICTIONS
(NASA) $16 \mathrm{p}$
N93-19969

Unclas 
- 


\title{
THREE-DIMENSIONAL NAVIER-STOKES HEAT TRANSFER PREDICTIONS FOR TURBINE BLADE ROWS
}

\author{
R. J. Boyle ${ }^{\dagger}$ \\ NASA Lewis Research Center \\ Cleveland, OH 44135 \\ P. W. Giel ${ }^{\dagger}$ \\ Sverdrup Technology, Inc. \\ Lewis Research Center Group \\ Cleveland, $\mathrm{OH} 44142$
}

\begin{abstract}
Results are shown for a three-dimensional NavierStokes analysis of both the flow and the surface heat transfer for turbine applications. Heat transfer comparisons are made with the experimental shocktunnel data of Dunn and Kim, and with the data of Blair for the rotor of the large scale rotating turbine. The analysis was done using the steady-state, three-dimensional, thin-layer Navier-Stokes code developed by Chima, which uses a multistage RungeKutta scheme with implicit residual smoothing. An algebraic mixing length turbulence model is used to calculate turbulent eddy viscosity. The variation in heat transfer due to variations in grid parameters is examined. The effects of rotation, tip clearance, and inlet boundary layer thickness variation on the predicted blade and endwall heat transfer are examined.
\end{abstract}

\section{Nomenclature}

$C_{p}$ - Pressure coefficient $\left(P-P_{\mathrm{IN}}^{\prime}\right) /\left(P_{\mathrm{IN}}^{\prime}-P_{\mathrm{EXIT}}\right)$

$P$ - Pressure

$R e$ - Unit Reynolds number

$C$ - Chord

$s$ - Fractional surface distance

$S t$ - Stanton number based on inlet conditions

$x$ - Fractional chordwise distance

$y$ - Distance normal to surface

$y^{+}$- Normalized distance from surface

$\delta$ - Full boundary layer thickness

$\nu$ - Kinematic viscosity

$\rho$ - Density

† Member AIAA

This paper is declared a work of the U.S. Government and is not subject to copyright protection in the United States.

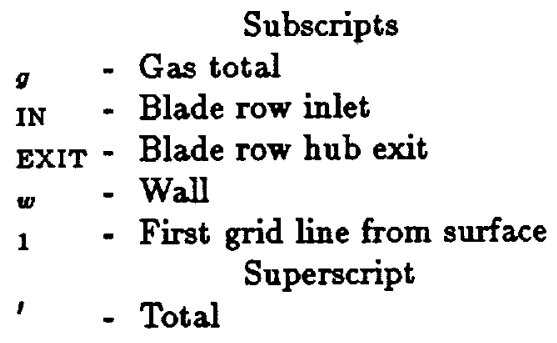

\section{INTRODUCTION}

Accurate heat transfer predictions are needed in turbomachinery designs for advanced propulsion systems. Improved heat transfer prediction capability allows for reduced coolant requirements for given heat loads to the turbine blades. Alternately, improved heat transfer predictions would allow for an increase in turbine inlet temperature for a given amount of coolant. Even if the blades are uncooled, accurate predictions are needed to determine blade temperatures during transients, since these temperatures determine thermal stresses. Experimental data show threedimensional heat transfer patterns on the blade and the endwall surfaces. ${ }^{(1-7)}$ These three-dimensional heat transfer patterns were observed in data from both cascade facilities and on rotating turbine blades. Blair ${ }^{(6)}$ showed heat transfer on the rotor surface in the tip region nearly double that in the midspan region, indicating the importance of clearance in determining blade heat transfer. Two-dimensional heat transfer analyses are unsuitable for predicting endwall heat transfer distributions, and do not account for clearance effects. The three-dimensional nature of the experimental data show the need for three-dimensional heat transfer analyses.

Comparisons have been made between predicted and measured vane and rotor heat transfer using three-dimensional Navier-Stokes analyses, ${ }^{(8-10)}$ typically for cases where neither tip clearance nor rotation were present. This paper shows comparisons between predicted and measured heat transfer for individual 
blade rows of turbine stages. Comparisons are shown with the heat transfer data of Dunn and $\mathrm{Kim}^{(7)}$, and with the data of Blair ${ }^{(6)}$. Dunn and Kim measured vane and rotor heat transfer in a shock tunnel for the Space Shuttle Main Engine(SSME), high pressure fuel turbine(HPFT), operating at the design turbine pressure ratio. Measurements were made at three spanwise locations for the stator and rotor of the first stage, and at midspan for the stator of the second stage. Blair measured heat transfer for the rotor of a low speed turbine in a large scale rotating rig over a range of Reynolds numbers and flow coefficients. Full span heat transfer data were obtained on both surfaces of the rotor, and on the hub endwall.

The heat transfer analysis was done using the steady-state three-dimensional analysis developed by Chima ${ }^{(11-12)}$. This is an explicit, finite-difference, thin-layer Navier-Stokes analysis. An algebraic turbulence model is used to calculate the turbulent eddy viscosity. One question which arises with respect to the clearance flow region is the degree of detail needed for calculating the flow in the gap between the top of the rotating blade and the stationary shroud. It is possible to generate a grid for the region on top of the blade in this gap, and a grid would be necessary to calculate the heat transfer on the top surface of the rotor. However, a simpler approach is to average the flow variables for the blade surface grid line when the grid is extended into the clearance region. Since part of the motivation for this work was to determine an efficient approach which gives accurate results, the simpler approach was used.

\section{DESCRIPTION OF ANALYSIS}

Chima ${ }^{(11)}$, and Chima and Yokota(12) give details of the three-dimensional, thin-layer Navier-Stokes analysis. Briefly, the code uses an explicit time marching algorithm, employing implicit residual smoothing. A four-stage Runge-Kutta scheme was used. A spatially varying time step along with a CFL number of 5 was used to speed convergence to the steady-state solution.

The analysis was done to determine if a simple, and therefore relatively fast, approach to tip clearance modeling would correctly predict the effect of clearance on rotor heat transfer. In the clearance region, above the rotor, the flow variables at the projected surface of the blade were averaged. The values for a point on the extended suction surface were averaged with a corresponding point on the extended pressure surface. Because of the distribution of points in the $\mathrm{C}$ grid, the averaged points were approximately the corresponding point normal to the mean camber line. In this region the relative velocities at the projected sur- face of the blade were not set equal to zero. Rather, they were calculated in the same way as in the wake region. In the clearance region there is no pressure differential across the rotor. Fluid is induced to flow from the high pressure region adjacent to the pressure surface into the low pressure region adjacent to the suction surface.

The transition locations were calculated using the midspan transition criteria. The start of transition and the length of transition in terms of distance from the stagnation point were determined using the procedure described in reference 13 for the midspan flow conditions. As discussed in reference 13, the transition prediction used the procedure recommended by Mayle, ${ }^{(14)}$ in which the transition location is a function of Reynolds number, freestream turbulence, and the blade passing frequency of the upstream blade row. In the course of this work the effects of variation in the turbulence model were examined. Changing the model resulted in different heat transfer levels. However, the same relative three-dimensional patterns were observed. A model was chosen for the three-dimensional heat transfer calculations, and it is expected that other models would yield similar three-dimensional effects. The turbulence model employed near wall damping, and wall functions were not used. All cases were run with a specified wall temperature.

C-type grids, which facilitate obtaining accurate flow and heat transfer solutions in the leading edge region, were used. The leading edge region is a region of high heat transfer on both the blade surface and on the endwall in front of the blade. Grids were generated using the code TCGRID developed at Lewis by Chima, Kirtley, and Tweedt, ${ }^{(15)}$ with the blade and endwall geometry defined as in the MERIDL program of Katsanis(16). The TCGRID program interpolates this information to generate input data for a relatively small number of two-dimensional blade-to-blade grids. The subroutine within the TCGRID program that is used to generate these two-dimensional grids is based on Sorenson's GRAPE code ${ }^{(17)}$. After the blade-toblade grids were generated, the resulting grids were interpolated to give grids for each spanwise grid plane.

When generating the grids it was necessary to determine the spacing of the first grid line from the surface. It is not the physical spacing, $y_{1}$, but rather the normalized spacing $y_{1}^{+}$, that should be specified to obtain accurate heat transfer results. An a priori estimate of $y^{+}$was calculated as given by Boyle ${ }^{(18)}$, except that the gas-to-wall temperature ratio was explicitly accounted for. The expression used for the reference $y^{+}$is:

$$
y_{\mathrm{REF}}^{+}=0.17 y_{1} R e^{0.9}\left(T_{q} / T_{w}\right)^{1.5} / C^{0.1}
$$


where $R e$ is the unit Reynolds number based on freestream conditions at the blade row exit. $y_{1}$ is the distance from the first grid line to the wall, and $C$ is the axial chord. The ratio $T_{q} / T_{w}$ is important only when the gas total temperature to wall temperature ratio is large, as it was in some of these comparisons. An exponent of 1.5 was used to account for the effect of temperature on both density and viscosity. The temperature ratio term was included because it improved the agreement between the $y_{R E F}^{+}$used in generating the grid, and the maximum value of $y_{1}^{+}$calculated from the Navier-Stokes solution. In all of the cases presented, the spacing of the first grid line from the hub and shroud was maintained at the same value as the spacing of the first grid line from the blade.

\section{RESULTS and DISCUSSION}

Because of the relatively long computational times involved in three-dimensional $\mathrm{Navier-Stokes} \mathrm{cal-}$ culations, it is necessary to determine the smallest grid size that results in accurate predictions. First, the grid size parameters and the near wall spacing, along with the endwall boundary thickness will be examined to show their relative importance in calculating accurate turbine blade heat transfer. Next, the heat transfer and pressure distribution comparisons with experimental data will be made for the individual blade rows. Grid parameter results. The first stage stator of the SSME high-pressure fuel turbine was used to determine the appropriate grid parameters. The flow conditions are those of the low Reynolds number case of Dunn and Kim. (7) The grid sensitivity study was done assuming fully turbulent flow. Figure 1 shows the geometry and a typical grid used for the heat transfer predictions, with the grid clustered near each of the solid walls. The chord is shorter at the hub than at midspan, which results in an underturning of the flow at the hub. Figure 2 shows the effects of grid parameters primarily on Stanton number, but also on the surface pressure distribution, and on the calculated value of $y_{1}^{+}$. Results are shown for a combination of five different grids, and Table I summarizes the parameters for the different grids. The choice of grid parameters was influenced by the grid sensitivity results presented by Boyle ${ }^{(18)}$ for a two-dimensional Navier-Stokes heat transfer analysis. Note that grids $D$ and $E$ were generated with different grid input parameters, which resulted in locally different grids. These two grids differed in terms of grid spacing around the blade, and in orthogonality to the vane surface, but had the same number of grid lines and near-wall spacing. Both were felt to be acceptable grids, but neither was felt to be superior to the other in an overall sense.

Figure 2a shows Stanton number results for two cases which differ in the number of streamwise grids by comparing grids $A$ and $B$. The number of streamwise grids is the total number of grid lines which extend out from the blade surface or from the C-grid cut line in the wake region. Grid A had 214 streamwise grid lines, of which 68 were in the wake; grid B had 145 streamwise grid lines, of which 40 were in the wake. The coarser grid with 145 lines had nearly the same Stanton number distribution as the finer grid, showing that a relatively sparse grid could be used around the blade for the heat transfer predictions.

Figure $2 b$ shows the effect of varying the nearwall spacing on Stanton number using grids $C$ and D. Increasing $y_{R E F}^{+}$from 1.2 to 2.3 had little effect on the blade surface Stanton number.

Figure 2c shows the effect on the Stanton number of grid stretching in the spanwise direction. Grids B and $E$, used for the comparisons, had the same spacing for the first grid line off each endwall. Because grid B had only 43 spanwise grid lines, it was stretched considerably more. The ratio of $\Delta y_{2}$ to $\Delta y_{1}$ was 1.6 for grid $B$, and this ratio was 1.3 for grid $E$. $\Delta y$ is the distance between adjacent grid lines in the radial direction, with $\Delta y_{1}$ being the distance between the hub or tip and the first grid line off the wall. The effect of grid stretching is very noticeable on vane surface heat transfer. This is somewhat surprising since the grid variation is only in the spanwise direction, and not in a direction normal to the blade. The span-topitch ratio for this case is 1.1 , so that the grid outward from the blade was stretched about the same as grid $\mathrm{E}$ was stretched in the spanwise direction. With C-type grids, the grid extends from the blade surface only to the midchannel, and there is no clustering near the midchannel. The same number of lines in the spanwise and blade-normal directions results in far greater stretching in the spanwise directions for all but very low span-to-pitch ratios.

Generating grids for turbine blade geometries involves compromises. Because of the highly turned geometry, no one grid is optimum over the entire flow field. Sensitivity of heat transfer to choice of grid optimization can be seen by comparing results in figures $2 b$ and $2 c$ for the same grid parameters. The Stanton number results do not differ significantly between grid $D$ in figure $2 b$ and grid $E$ in figure $2 c$.

Figure 2d shows the effect on surface pressures comparing grids $\mathbf{B}$ and $\mathbf{E}$. The differences are smaller than one might expect based on the differences in the surface heat transfer. These almost contradictory results suggest that the heat transfer is influenced by the analysis's ability to calculate the secondary flows across the endwall.

Figure $2 \mathrm{e}$ shows calculated $y_{1}^{+}$values on the blade 
surface for grids C and D. For both values of $y_{\mathrm{REF}}^{+}$ the maximum value calculated from the Navier-Stokes analysis is only slightly in excess of the a priori estimate give by equation 1 . Because this example is for a gas-to-wall temperature ratio of 1.9 , neglecting the gas-to-wall temperature ratio term in calculating $y_{\mathrm{REF}}^{+}$would reduce the value by nearly a factor of 3 . If the gas-to-wall temperature ratio term was neglected in calculating $y_{R E F}^{+}$, the value of $y_{R E F}^{+}$would be significantly less than the maximum value of $y^{+}$calculated using the Navier-Stokes analysis.

Grids of 400,000 points took approximately 2.5 seconds of CPU time on a Cray YMP computer per iteration. Typically, heat transfer converged within 2500 iterations, even if not initialized with a similar flow field. Less than $8 \mathrm{MW}$ of core were required for this number of grid points.

Figure 3 shows the effect of grid stretching on the endwall heat transfer. After examining the results shown in figure $2 c$ it is not surprising that this effect is very large. Viewing these differences as uncertainties in comparisons with experimental measurements shows that coarse spanwise grids result in unacceptable computational errors. The strong sensitivity of the heat transfer to grid stretching, coupled with the relatively weak sensitivity to the near-wall spacing, suggest that the effect of trading increased near-wall spacing for reduced stretching be further examined. Inlet boundary layer effect. Figure 4 shows the blade and endwall heat transfer assuming an inlet boundary layer on each endwall equal to 30 percent of the full span. This inlet boundary layer thickness was chosen arbitrarily large to illustrate its effect on blade and endwall heat transfer. Inlet boundary layer thicknesses of the same order as 30 percent of span have been reported measured in endwall heat transfer experiments. $(1,4)$ While the effect of an inlet boundary layer on the heat transfer distribution is not as great as the effect of grid stretching, this effect is noticeable. If a boundary layer is present in the test, it should be included in the analysis.

Experimental data comparisons. Figure 5a compares predicted surface pressures with the data of Hudson, Gaddis, Johnson, and Boynton ${ }^{(19)}$ taken at the NASA Marshall Space Flight Center(MSFC) turbine test facility. It was felt to be appropriate to compare pressure predictions with the MSFC data, because these tests were aimed at obtaining accurate steady-state pressures. Data are shown at 10,50 , and $90 \%$ of span. The Navier-Stokes analysis considers only an isolated blade row. The inlet total pressure and blade row pressure ratio for this and subsequent blade rows were obtained from the quasi-three-dimensional flow analysis code $\mathrm{MTSB}^{(20)}$, using the experimental overall two-stage turbine pressure ratio. Grid $\mathrm{C}$ was used for the Navier-Stokes analysis. The Navier-Stokes analysis predicted the surface pressures at 50 and $90 \%$ of span reasonably well, but not as well at $10 \%$ of span. This may be due to the circumferential nonuniformity of the stator cutback. The analysis used the average cutback, but the instrumented vanes might have been in a passage with a different amount of cutback.

Figure 5b shows heat transfer comparisons for the low Reynolds number data of Dunn and Kim. ${ }^{(7)}$ The low Reynolds number cases are compared so as to minimize uncertainties associated with grid spacing. Experimental and predicted Stanton numbers for all blade rows were based on the first stator inlet density and velocity. Each endwall had an inlet boundary layer thickness of $8 \%$ of span, based on the flow and geometry upstream of the stator. Both pressure and suction surface data indicate a longer than predicted transition length. This accounts for the overprediction of the Stanton number near a third of the suction surface distance. The analysis is in reasonably good agreement with the data for the rearward portion of the pressure surface, and both show little spanwise variation in heat transfer. On the suction surface the analysis agrees reasonably well with the data in the fully turbulent region at $10 \%$ of span, and underpredicts the heat transfer at $50 \%$ of span close to the trailing edge. The data show the lowest suction surface heat transfer at $90 \%$ of span. The analysis predicts the correct trend in spanwise heat transfer variation, but predicts a somewhat higher heat transfer at $90 \%$ of span. The disagreement between the analysis and the heat transfer data does not appear to be due to the disagreement between the the analysis and the surface pressure data. The poorest agreement in surface pressures was at $10 \%$ of span, where the agreement in heat transfer is as good as at the other spanwise locations. The results in this figure and in figure 2 further indicate the importance of spanwise stretching. On the suction surface the data show greater spanwise variation in heat transfer than was predicted. The results in figure $2 c$ show lower heat transfer at 10 and $90 \%$ of span in the rearward portion of the suction surface for the finer spanwise grid.

Figure 6 shows the predicted heat transfer for the first stage rotor of the SSME high pressure fuel turbine. The analysis was done assuming a smooth blade surface based on the analysis presented in reference 18 , which concluded that the blades are hydraulically smooth at this Reynolds number. Heat transfer distributions are shown on both the unwrapped surface of the rotor, and on the hub endwall. The analysis was done using a $145 \times 40 \times 65$ grid, with a $y_{R E F}^{+}$of 2 ., and a rotor tip clearance of $2.2 \%$ of span. The inlet 
radial profile for the rotor analysis was obtained using the circumferential average of the stator exit results. The highest heat transfer occurs just in front of the leading edge, and is very localized. The second highest heat transfer in the blade region is in the throat region. Dunn and $\mathrm{Kim}^{(21)}$ gave two measurements of endwall Stanton numbers. The values were 0.0065 and 0.007 at $20 \%$ and $60 \%$ of the rotor chord, respectively.

Figure 7 compares predicted and measured heat transfer at 10,50, and 90 percent of span. The analysis underpredicts the leading edge heat transfer, but this was expected since the turbulence model did not account for any augmentation in heat transfer due to free stream turbulence prior to transition. Depending on the correlation used, an increase in the leading edge heat transfer of up to $40 \%$ could be expected. The predicted heat transfer agrees well with the experimental data along the pressure surface. On the suction surface the analysis agrees well with the data, except in the transition region, and near the trailing edge at $90 \%$ of span. The disagreement with the data in the transition region may not be the fault of the transition model, but rather the defining of stagnation points from which boundary layers are calculated to determine the start of transition. In a three-dimensional flow field there are ambiguities associated with the determination of the stagnation line. The analysis shows a smaller variation in heat transfer between 50 and $90 \%$ of span than the experimental data. However, in the clearance model there is no flow resistance at the top of the blade, and this assumption would result in higher than actual flow in the tip region.

To better understand the behavior of the calculations, it is useful to show results for different assumptions; comparing results for the different assumptions should clarify the factors determining the heat transfer. Figure 8 shows the blade heat transfer assuming a shrouded rotor. The outer casing rotates with the rotor, and there is no clearance gap. These results can be compared with those shown in figure 6 . Close to the trailing edge on the suction side, the heat transfer is higher without clearance. Everywhere else in the tip region, the Stanton number is lower when there is no clearance. Based on these data alone the assumption made for flows in the clearance gap appears to underestimate the effect of tip clearance, does give the correct trend in heat transfer.

Figure 9 shows the vane surface Stanton numbers for the second stage stator. This stator is similar to the first stage stator, but there is no cutback at the trailing edge. The heat transfer is similar to that for the first stage vane. The three-dimensional effects on the vane heat transfer are noticeable, and show greater spanwise symmetry than for the first vane. This result is essentially due to the absence of the cutback for the second stage vane. Figure 10a compares midspan heat transfer predictions with the data of Dunn and $\mathrm{Kim}^{(7)}$. Except at the leading edge, where, as expected, the predicted heat transfer is lower than measured, the analysis overpredicts the blade surface heat transfer. Figure 10b compares pressure distributions at 10,50 and $90 \%$ of span with the data of Hudson et al. ${ }^{(19)}$. This comparison agrees better with the data than the pressure distribution for the first stage vane. Since the second stator has no cutback, there is less passage-topassage variation in its exiting flow field. The absence of a cutback could account for the better agreement with the data for the second stage vane.

Figure 11 shows the rotor surface heat transfer comparisons for the data of Blair. The analysis was done with a $145 \times 40 \times 65$ grid. The rect angular shape of unwrapped blade the plot is the result of using a normalized surface distance, where the normalization factor is a function of span. Comparisons for the suction and pressure surfaces show that in both the predictions and experimental data there are very high heat transfer rates in the tip region on the suction surface. Because this high heat transfer is in the tip region, one is likely to assume that this high heat transfer is the result of clearance flows. However, it should be noted that there is high heat transfer in the hub region at almost the same surface distance. The suction surface heat transfer in the hub region is higher than at midspan, but not as high as in the tip region. The analysis correctly predicts this three-dimensional pattern. Figure 12 shows a calculation for the same conditions as the prediction in figure 11, except that there is no clearance and the shroud rotates with the rotor. In the tip region the suction surface heat transfer is significantly lower than in figure 11 , showing the relative importance of these phenomena.

\section{CONCLUSIONS}

The results of this work showed that a threedimensional thin-layer Navier-Stokes analysis was able to predict heat transfer with reasonable accuracy. This result was true for cases with and without rotation. A relatively simple, and therefore computationally efficient, tip clearance model gave useful results. This model resulted in good agreement with experimental data with respect to the heat transfer on the surfaces of the blade in the tip region for the data of Blair, but underpredicted the tip clearance effect for the data of Dunn and Kim. However, this model, in which the flow variables were averaged at the extended surface of the blade in the tip region, gives no information with respect to the heat transfer on the tip surface of the blade. Nonetheless, it a useful tool for three 
dimensional heat transfer analysis, and this approach warrants further investigation.

Grid sensitivity studies showed that heat transfer was most sensitive to the grid stretching. Both blade and endwall heat transfer were highly dependent on spanwise grid stretching. Heat transfer was more sensitive to this parameter than to variations in near wall spacing, streamwise grid density, or local optimization of the grid. These results show that, while it is desirable to maintain a close near wall spacing, this parameter might be relaxed in favor of less grid stretching in the interest of obtaining accurate and economical heat transfer predictions.

The results of the analysis showed that in a multiblade row analysis, the results of the npstream calculation should be used as the inlet condition for successive blade rows. Because of the relative motion of the blade rows, circumferential averaging of the flow variables was done. Although the averaging does not completely preserve the flow field, the boundary layers on the endwalls are maintained between blade rows. The effect of neglecting the inlet endwall boundary layers was not large in terms of the blade surface heat transfer. However, the inlet boundary layer thickness was important in accurately predicting endwall heat transfer.

\section{REFERENCES}

1. Graziani, R.A., Blair, M. F., Taylor, J. R., and Mayle, R. E., "An Experimental Study of Endwall and Airfoil Surface Heat Transfer in a Large Scale Turbine Blade Cascade, ASME J. of Engineering for Power, Vol. 102, No. 2 April, 1980.

2. Blair, M. F., "An Experimental Study of Heat Transfer and Film Cooling in Large-Scale Turbine Endwalls," ASME Journal of Heat Transfer, Vol 96, Pp.525-529, 1974.

3. York, R. E., Hylton, L.D., and Mihelc, M. S., "Experimental Endwall Heat Transfer and Aerodynamics in a Linear Vane Cascade," ASME Journal of Engineering for Gas Turbines and Power, Vol 106, pp.159-167, 1984.

4. Boyle, R. J, and Russell, L. M., "An Experimental Determination of Stator Endwall Heat Transfer," ASME Journal of Turbomachinery, Vol 112, pp.547-558, 1990.

5. Blair, M. F., "An Experimental Study of Heat Transfer in a Large-Scale Turbine Rotor Passage," ASME paper 92-GT-195, 1992.

6. Blair, M. F., "The Effects of Reynolds Number, Rotor Incidence Angle, and Surface Roughness on the Heat Transfer Distribution in a Large-Scale Turbine Rotor Passage," UTRC Report No. R91-970057-3, 1991.

7. Dunn, M. G., and Kim, J., "Heat Transfer and Pressure Measurements and Comparison with Prediction for the SSME Two-Stage Turbine," CUBRIC Report No 640I, March, 1992.

8. Hah, C., "Numerical Study of Three-Dimensional Flow and Heat Transfer Near the Endwall of a Turbine Blade Row," AlAA paper 89-1689, 1989.
9. Ameri, A. A., and Arnone, A., "Three Dimensional Navier-Stokes Analysis of Turbine Passage Heat Transfer," ALAA paper 91-2241, 1991.

10. Choi, D., and Knight, C. J., "Computation of 3D Viscous Linear Cascade Flows," ALAA Journal Vol. 26, No. 12, Dec., pp 1477-1482, 1988.

11. Chima, R.V., "Viscous Three-Dimensional Calculations of Transonic Fan Performance," AGARD Propulsion and Energetics Symposium on Computational Fluid Mechanics for Propulsion, San Antonio, Texas, May 27-31, 1991.

12. Chima, R.V., and Yokota, J.W., "Numerical Analysis of Three-Dimensional Viscous Internal Flows," AIAA paper 88-3522, 1988,(NASA TM-100878)

13. Dunn, M. G., Kim, J., Civinskas, K. C., and Boyle, R. J., "Time-Averaged Heat Transfer and Pressure Measurements and Comparison with Prediction for a Two-Stage Turbine," ASME paper 92-GT-194, 1992.

14. Mayle, R. E., "The Role of Laminar-Turbulent Transition in Gas Turbine Engines," ASME Journal of Turbomachinery Vol. 113, Oct., Pp. 509-537, 1991.

15. Chima, R.V., Personal communication.

16. Katsanis, T. and McNally, W.D., "Revised FORTRAN Program for Calculating Velocities and Streamlines on the Hub-Shroud Midchannel Stream Surface of an Axial-, Radial-, or Mixed-Flow Turbomachine or Annular Duct, Vol. I - User's Manual," NASA TN D-8430, 1977.

17. Sorenson, R.L., "A Computer Program to Generate Two-Dimensional Grids About Airfoils and Other Shapes by the Use of Poisson's Equation," NASA TM-81198, 1980.

18. Boyle, R.J., "Navier-Stokes Analysis of Turbine Blade Heat Transfer," ASME Journal of Turbomachinery Vol. 113, July, pp. 392-403, 1991.

19. Hudson, S. T., Gaddis, S. W., Johnson, P. D., and Boynton, J. L., "Cold Flow Testing of the Space Shuttle Main Engine High Pressure Fuel Turbine Model," AIAA paper 91-2503, 1991.

20. Boyle, R. J., Haas, J. E., and Katsanis, T., "Predicted Turbine Stage Performance Using Quasi-Three-Dimensional and Boundary Layer Analyses" AlAA Journal of Propulsion and Power Vol. 1, No. 3 pp 242-251, 1985.

21. Dunn, M. G., Kim, J., "Turbine Blade Platform, Blade Tip, and Shroud Heat Transfer," Published in the Proceedings of the Fourth Int. Symposium on Transport Phenomena and Dynamics of Rotating Machinery, Honolulu, Hawaii, April 5-8, 1992.

Table 1 - Characteristics of first stage stator grids

\begin{tabular}{|l|rrrrr|}
\hline Grid & A & B & C & D & E \\
\hline Streamwise No. & 214 & 145 & 145 & 145 & 145 \\
Pitchwise No. & 43 & 43 & 43 & 43 & 43 \\
Spanwise No. & 43 & 43 & 65 & 65 & 65 \\
$\mathrm{y}^{*}$ & 2.3 & 2.3 & 1.2 & 2.3 & 2.3 \\
\hline
\end{tabular}




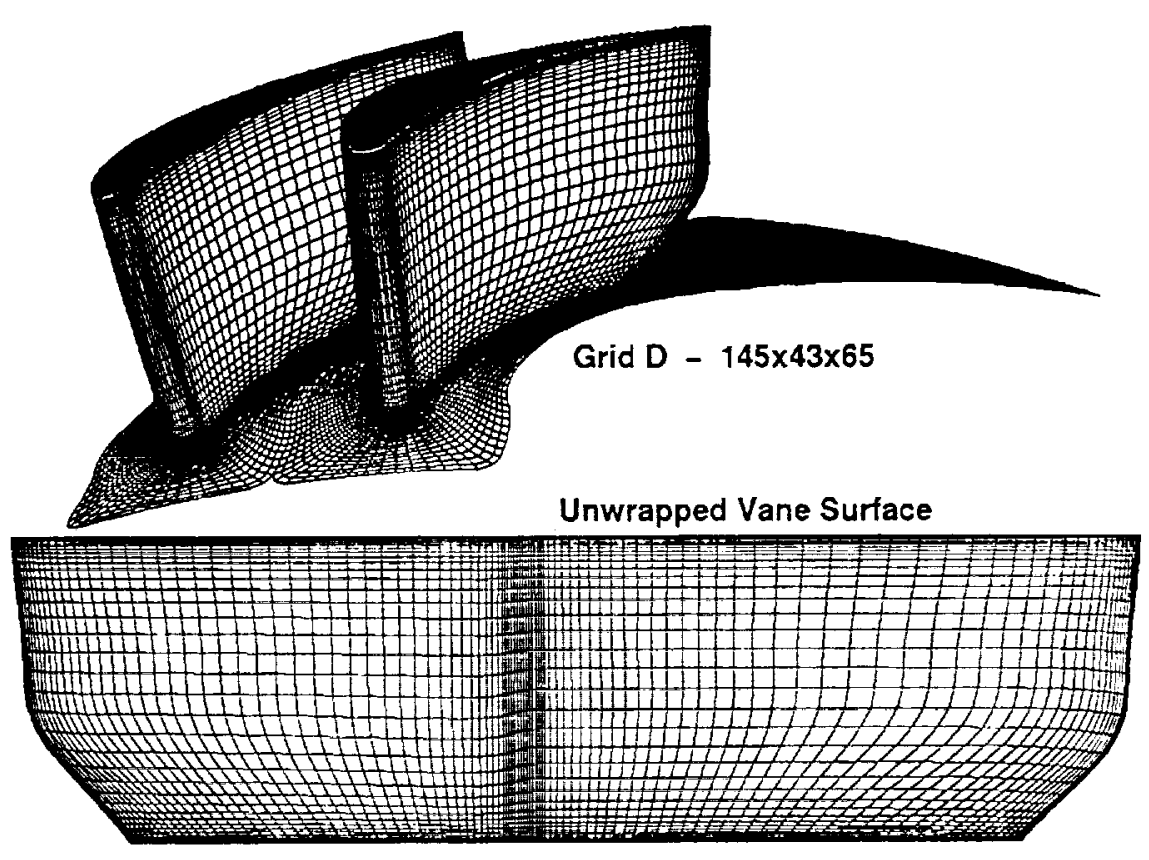

Figure 1. Geometry - Stator 1.

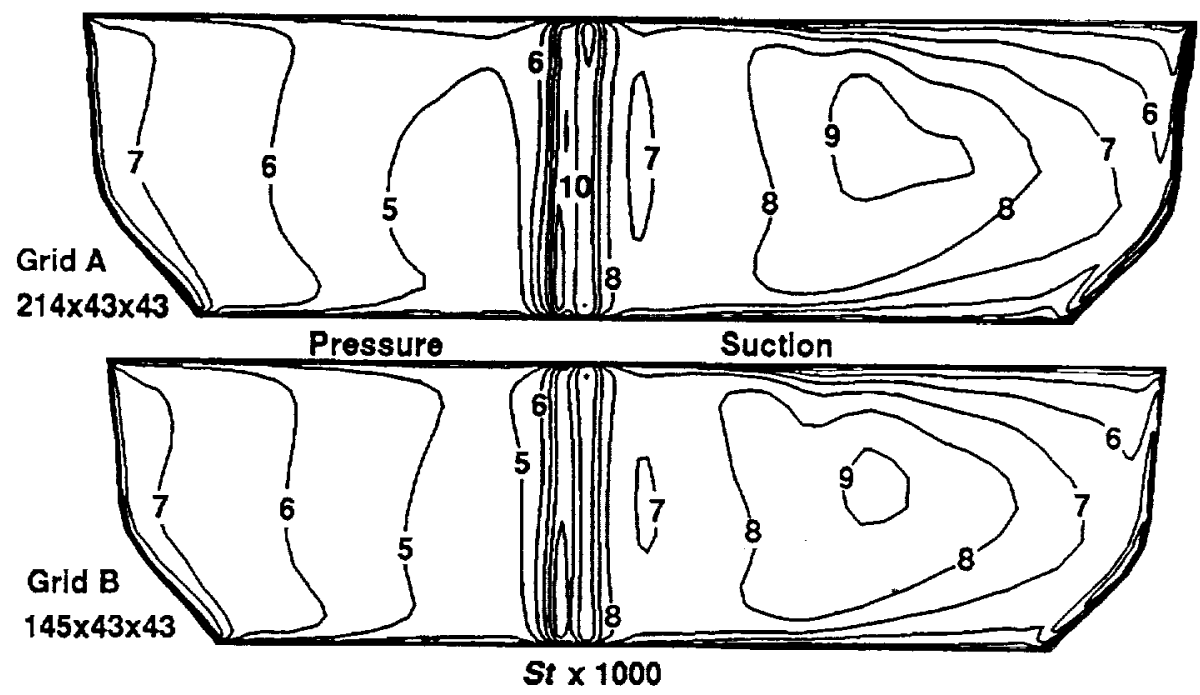

Figure 2a. Effects of streamwise grid density on vane heat transfer. 

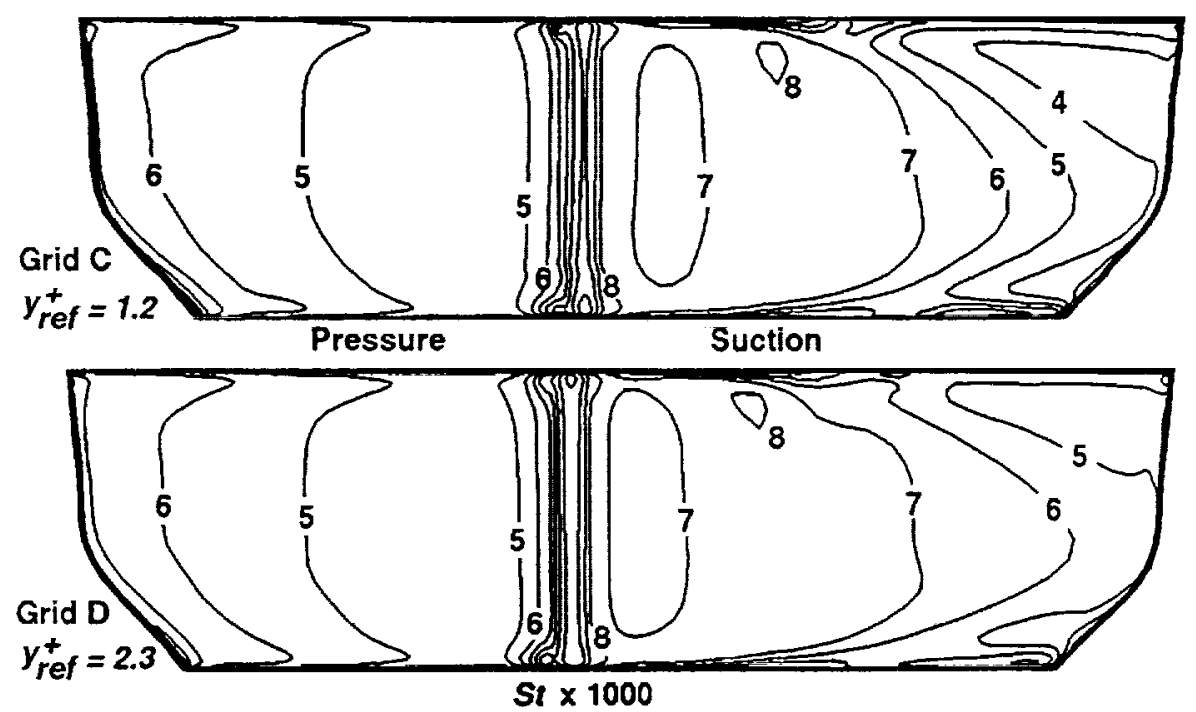

Figure 2b. Effects of near-wall grid spacing on vane heat transfer.

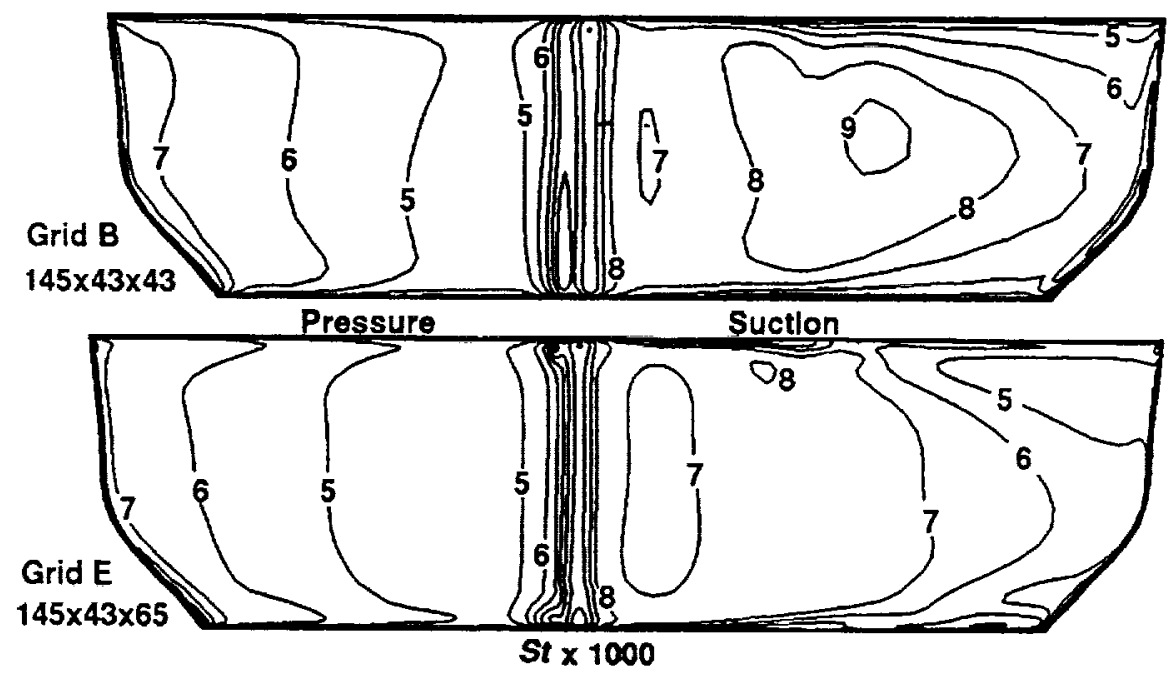

Figure 2c. Effects of spanwise grid stretching on vane heat transfer.

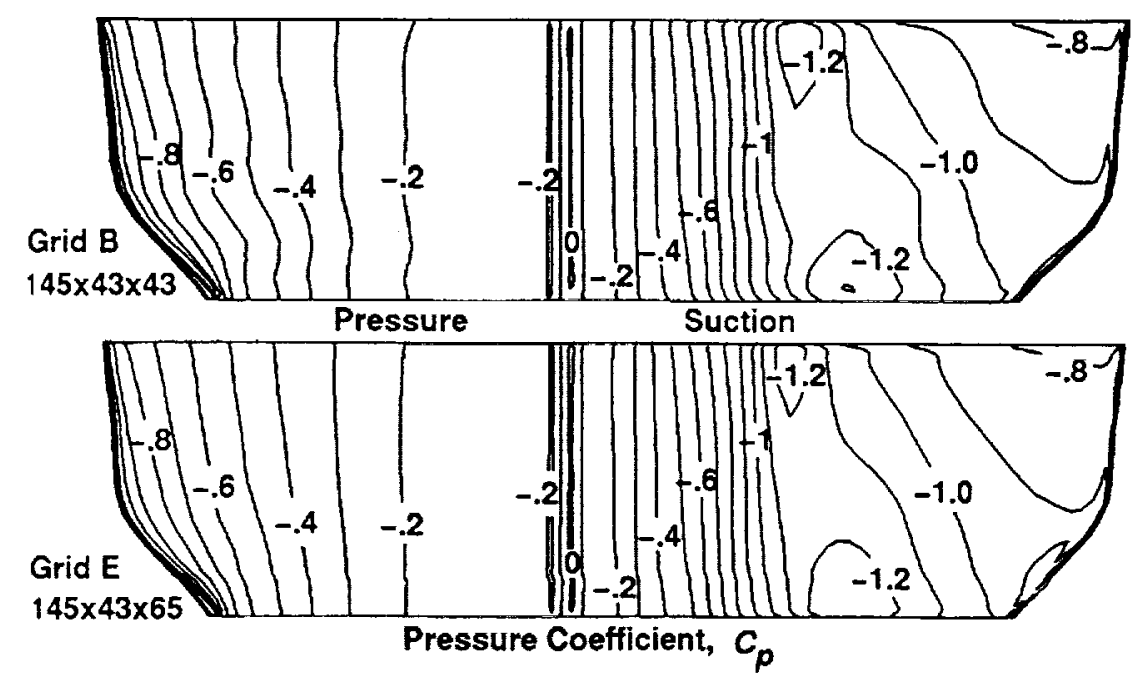

Figure 2d. Effects of spanwise grid stretching on vane surface pressure. 


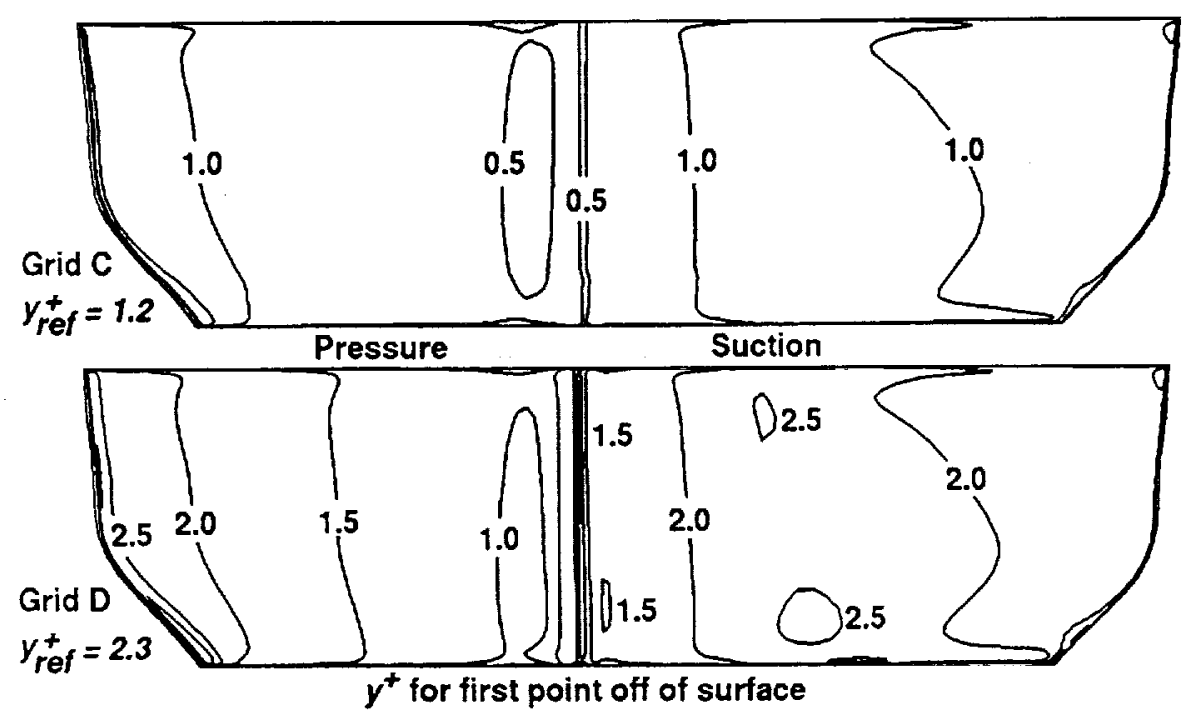

Figure 2e. Variation of $y^{+}$with near-wall grid spacing.

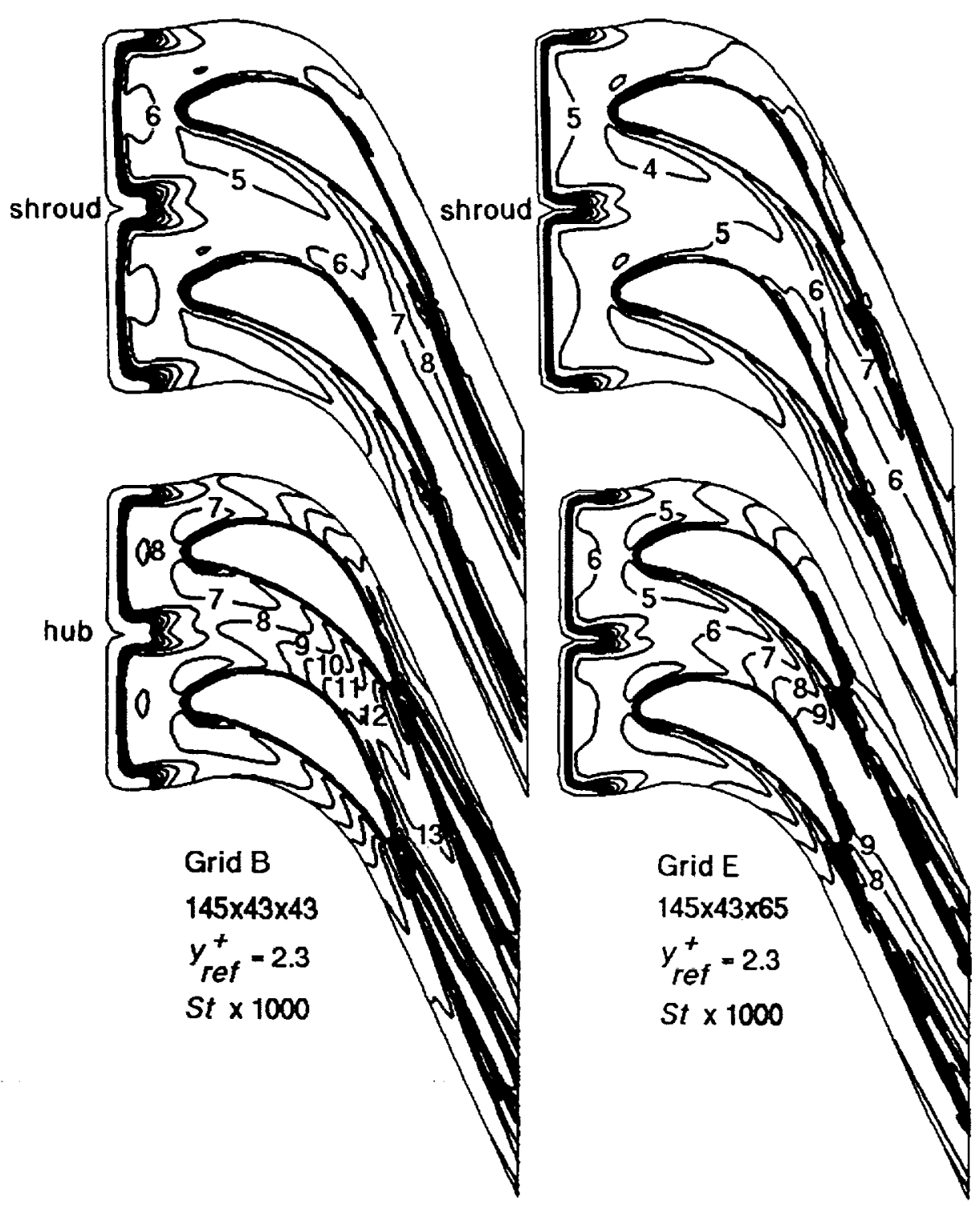

Figure 3. Effects of spanwise grid stretching on endwall heat transfer. 


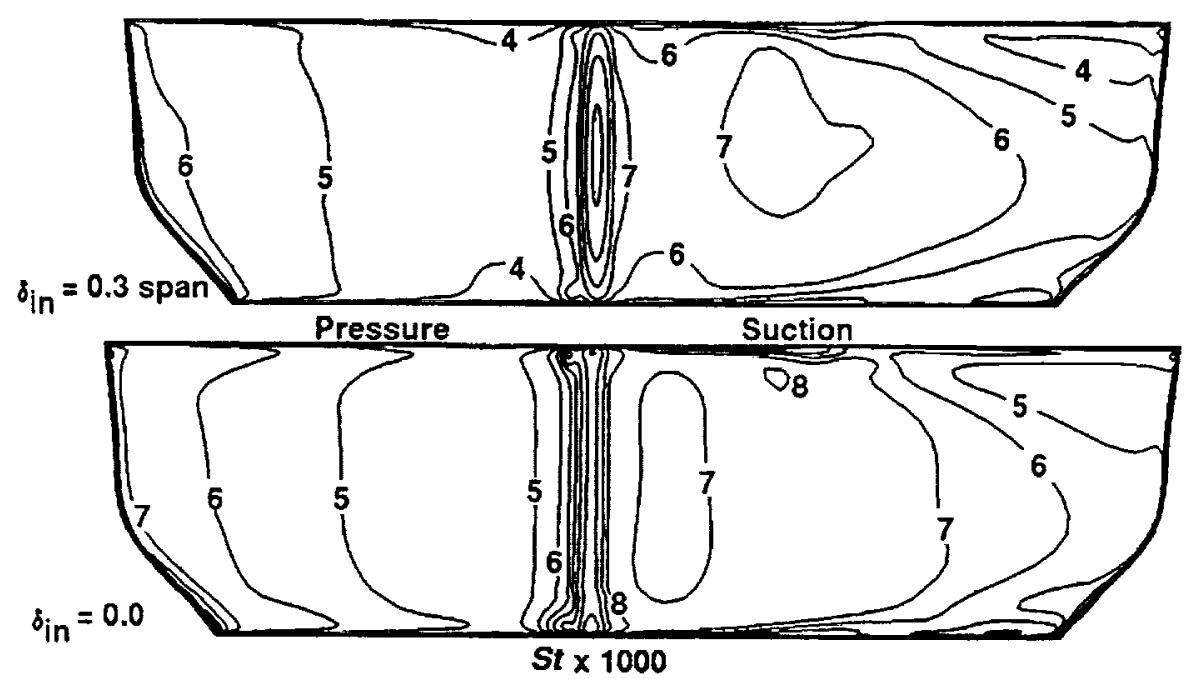

Figure 4a. Effects of inlet boundary-layer on vane heat transfer.

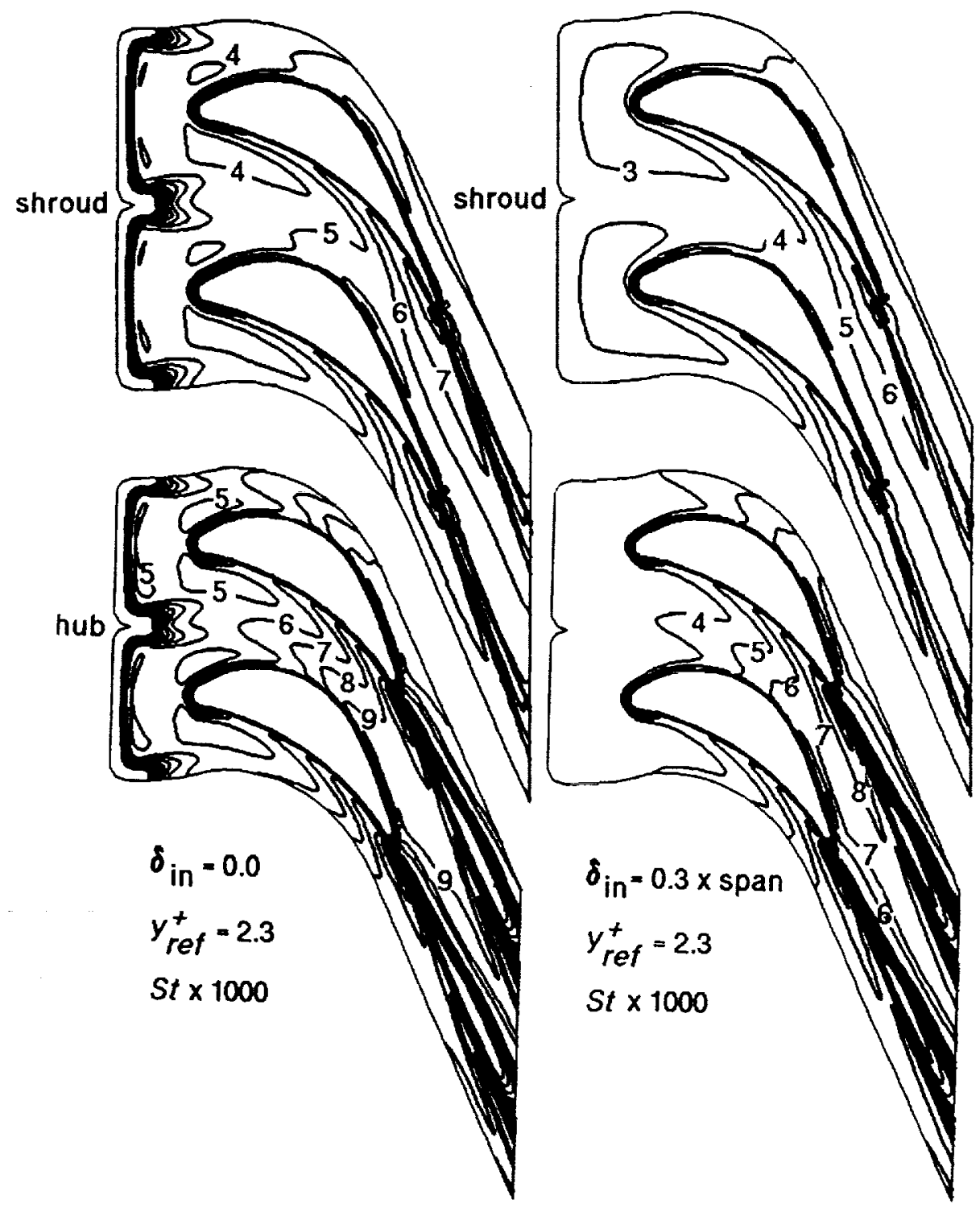

Figure 4b. Effects of inlet boundary-layer on endwall heat transfer. 


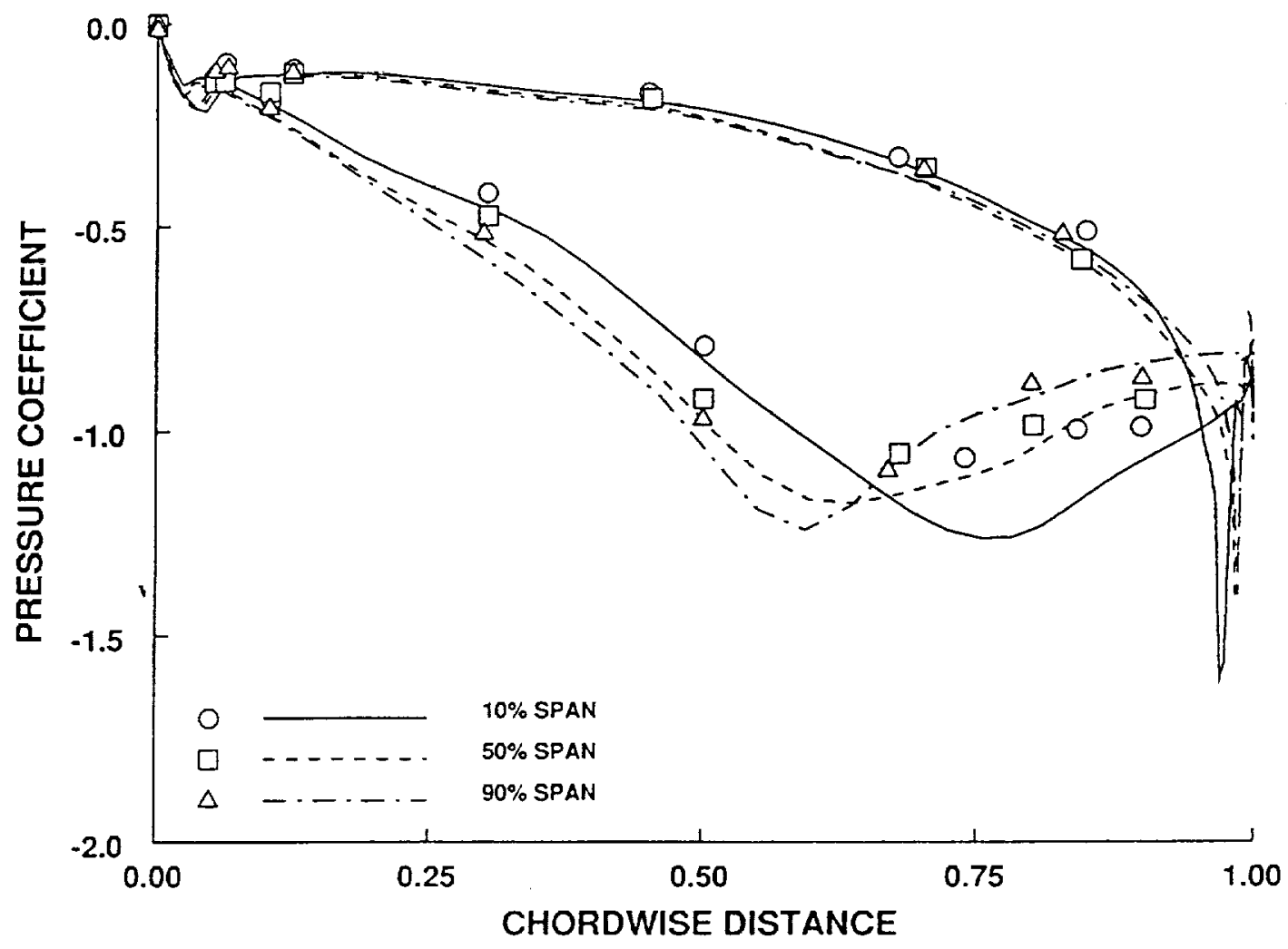

Figure 5a. Stator 1 Pressure Distribution (data of Hudson et al.).

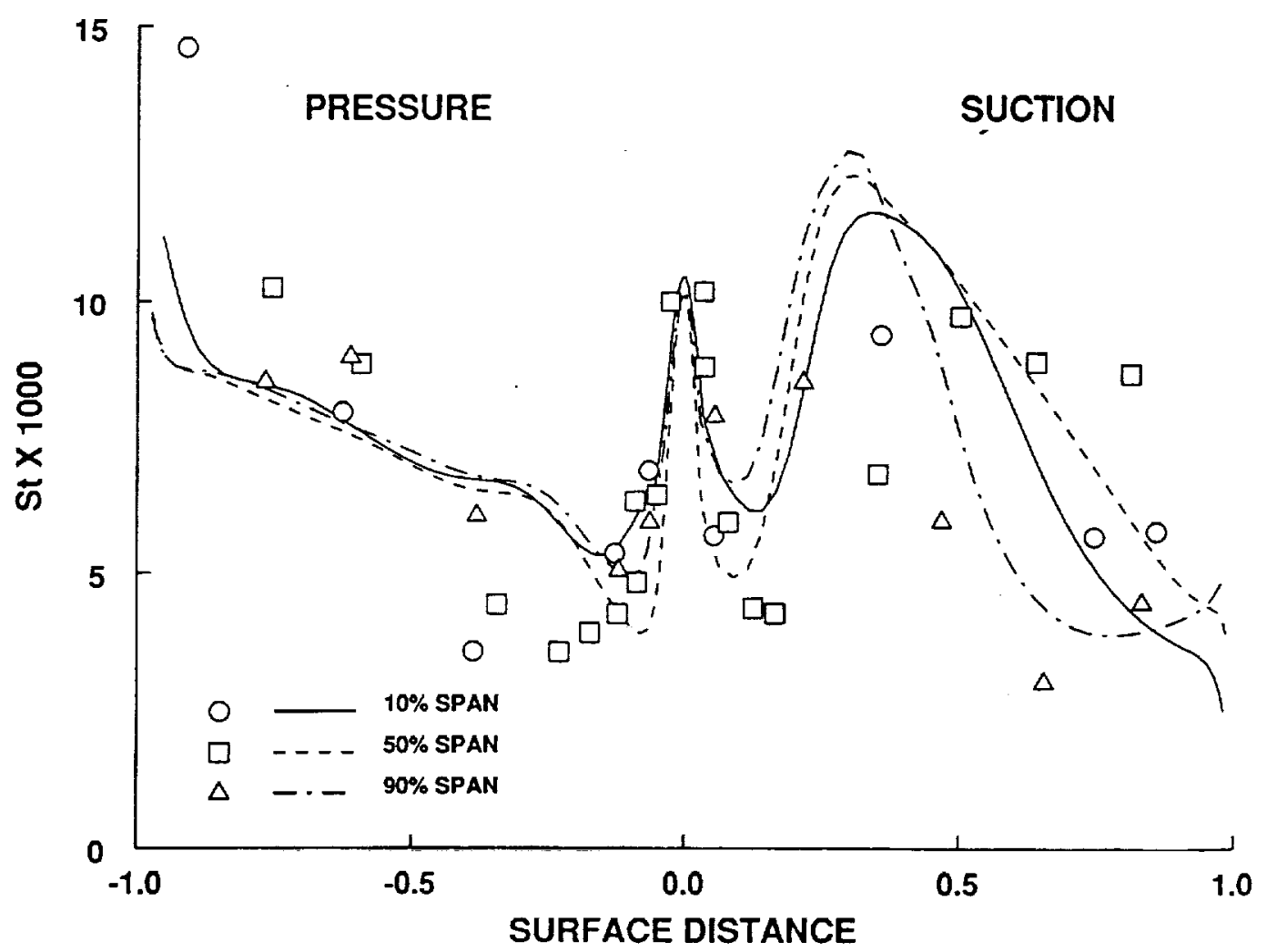

Figure 5b. Stator 1 Heat Transfer (data of Dunn and Kim). 


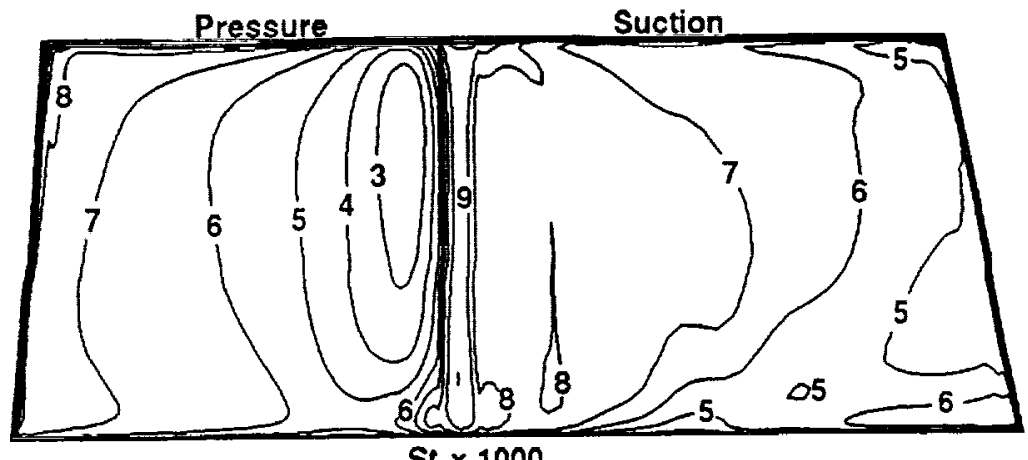

a) unwrapped rotor surface

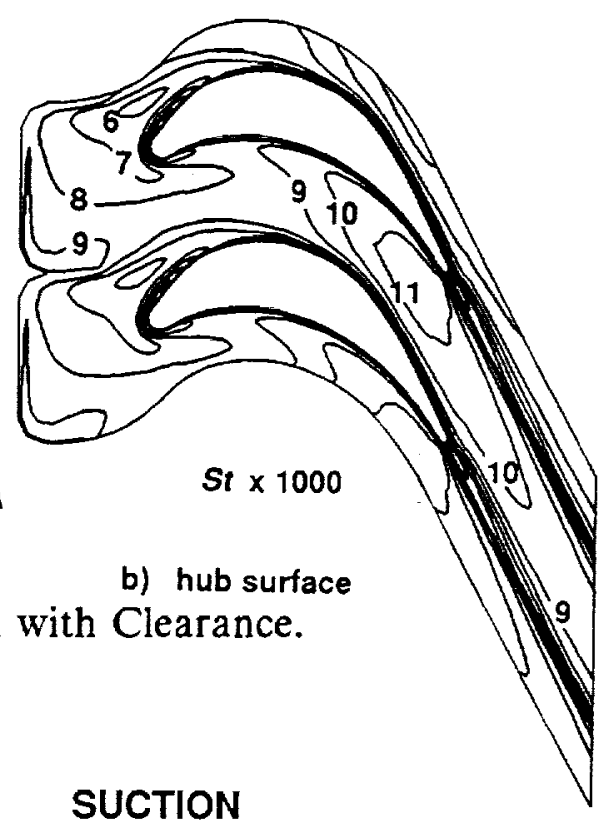

$\Delta$

$\Delta$

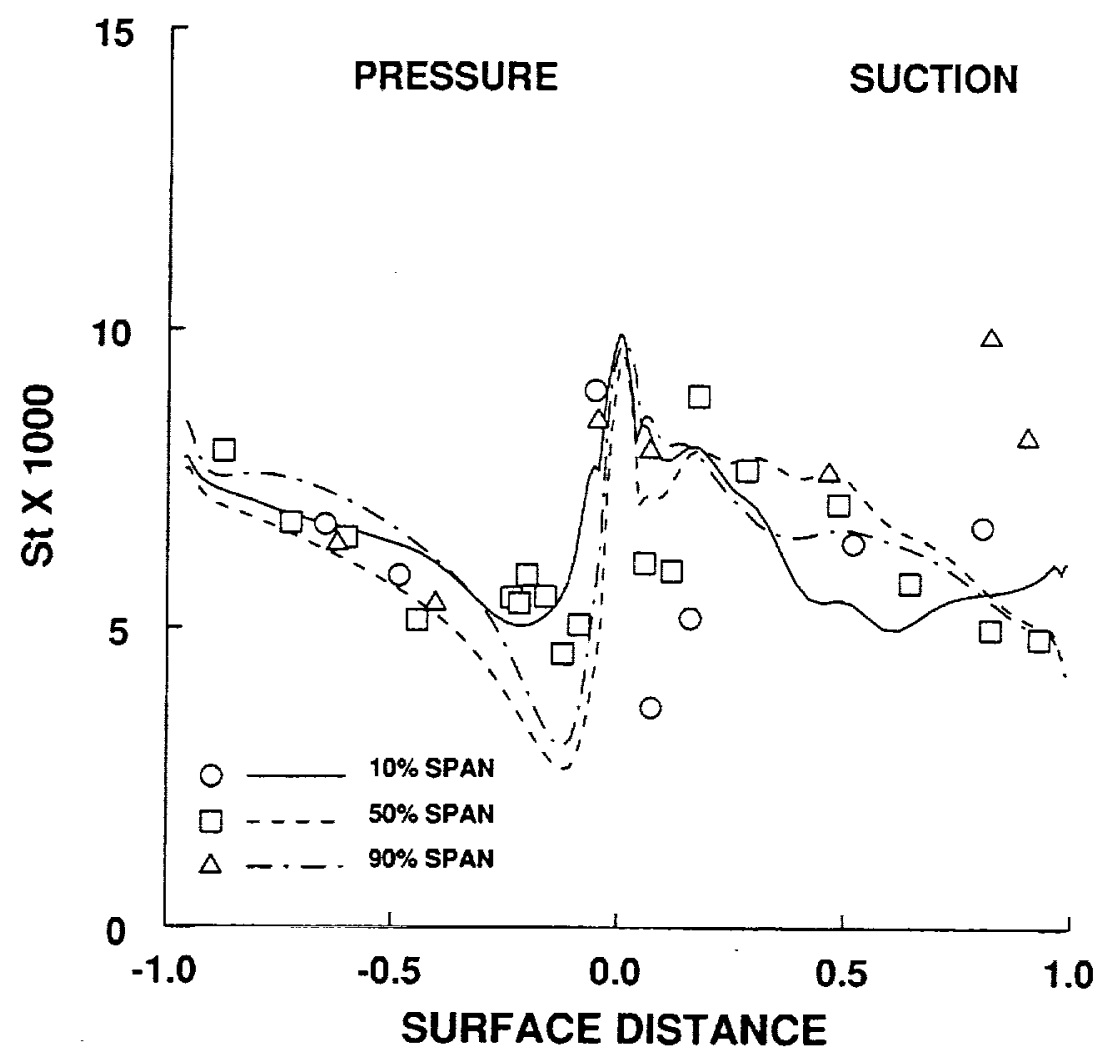

Figure 7. Rotor 1 Heat Transfer (data of Dunn and Kim).

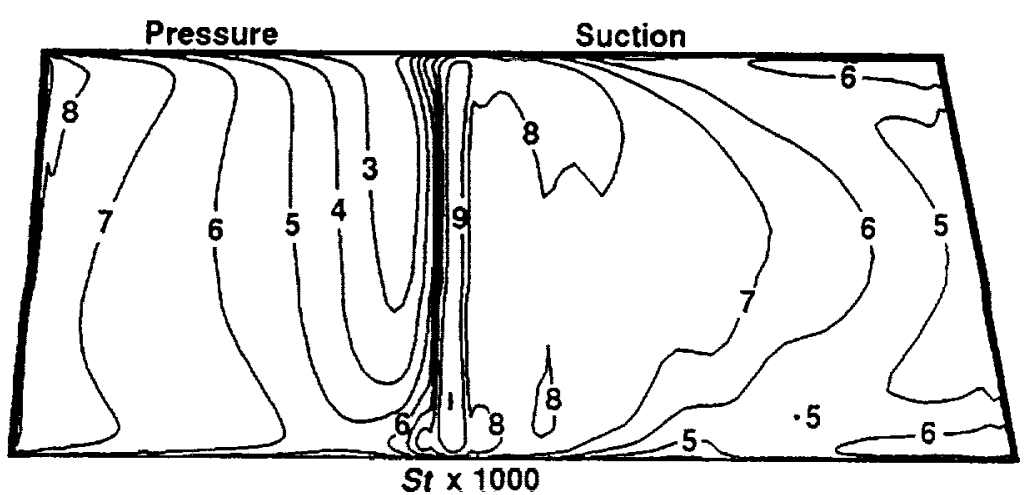

Figure 8. Rotor 1 Heat Transfer Calculation. Zero Clearance, Rotating Shroud. 


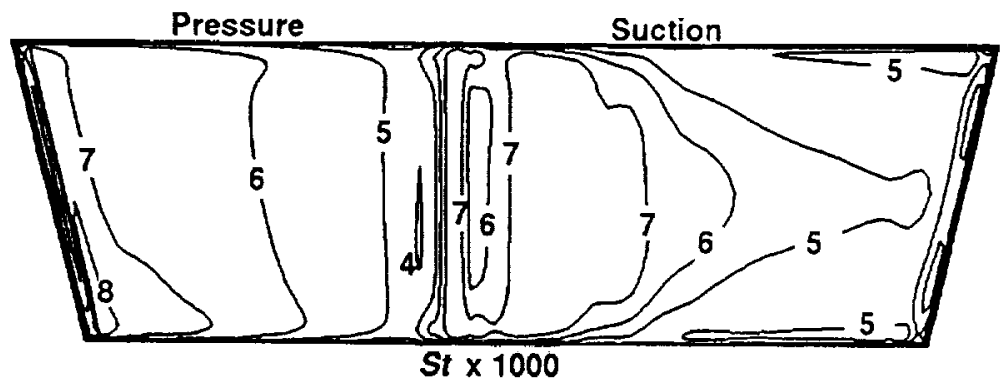

Figure 9. Stator 2 Heat Transfer Prediction.

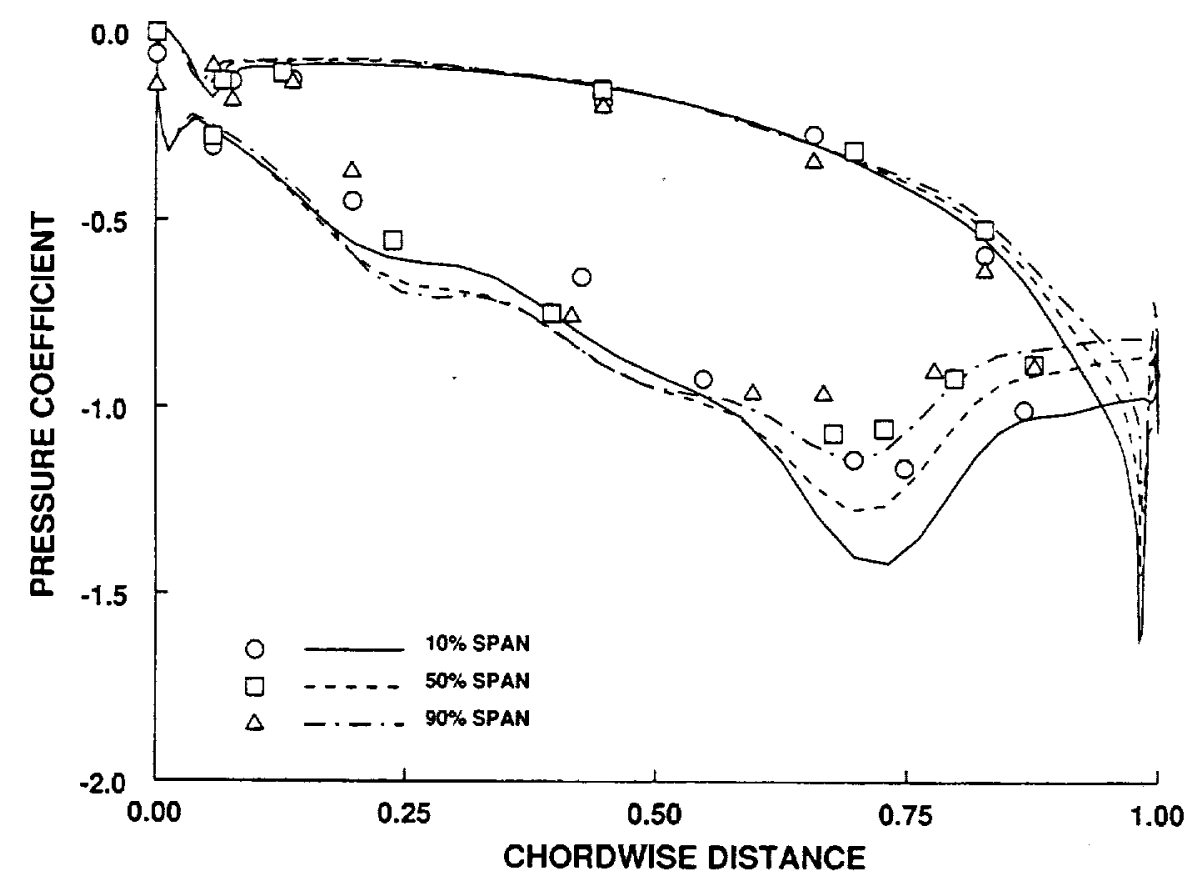

Figure 10a. Stator 2 Pressure Distribution (data of Hudson et al.).

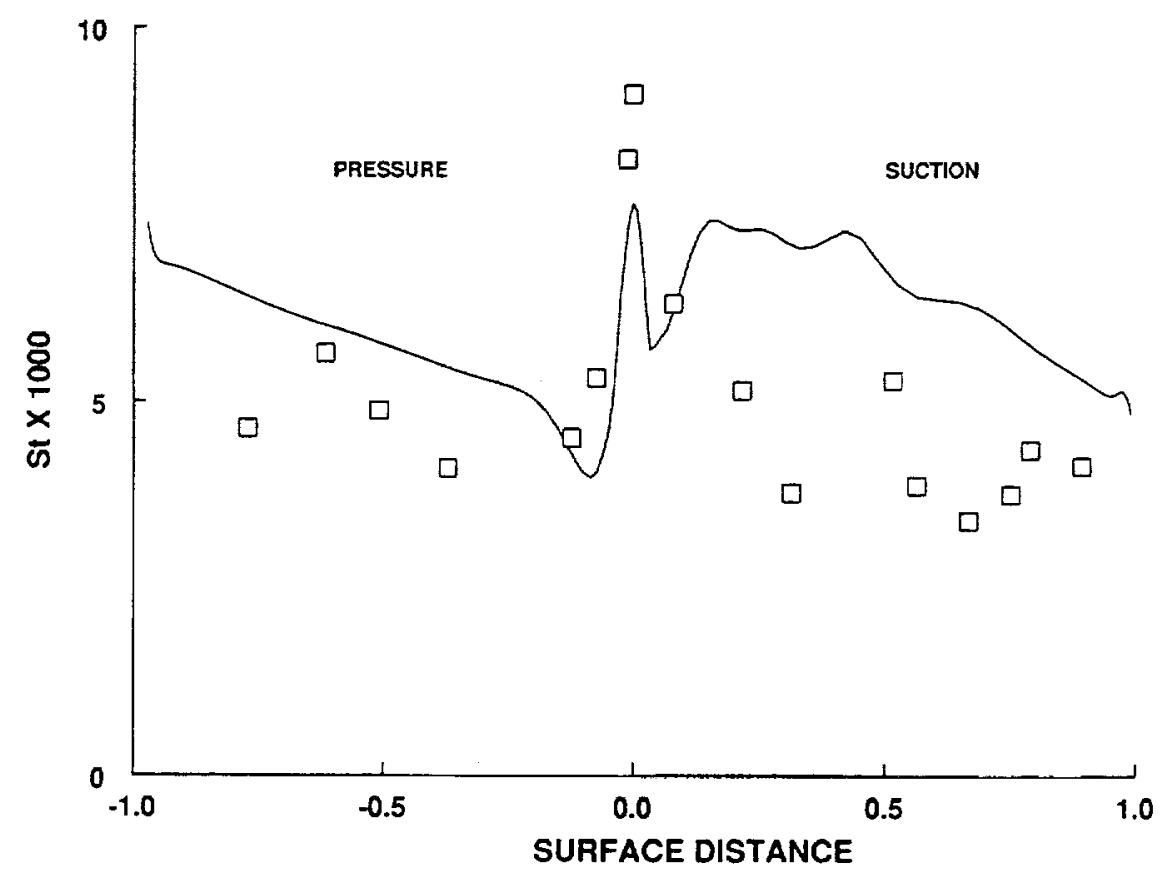

Figure 10b. Stator 2 Midspan Heat Transfer (data of Dunn and Kim). 


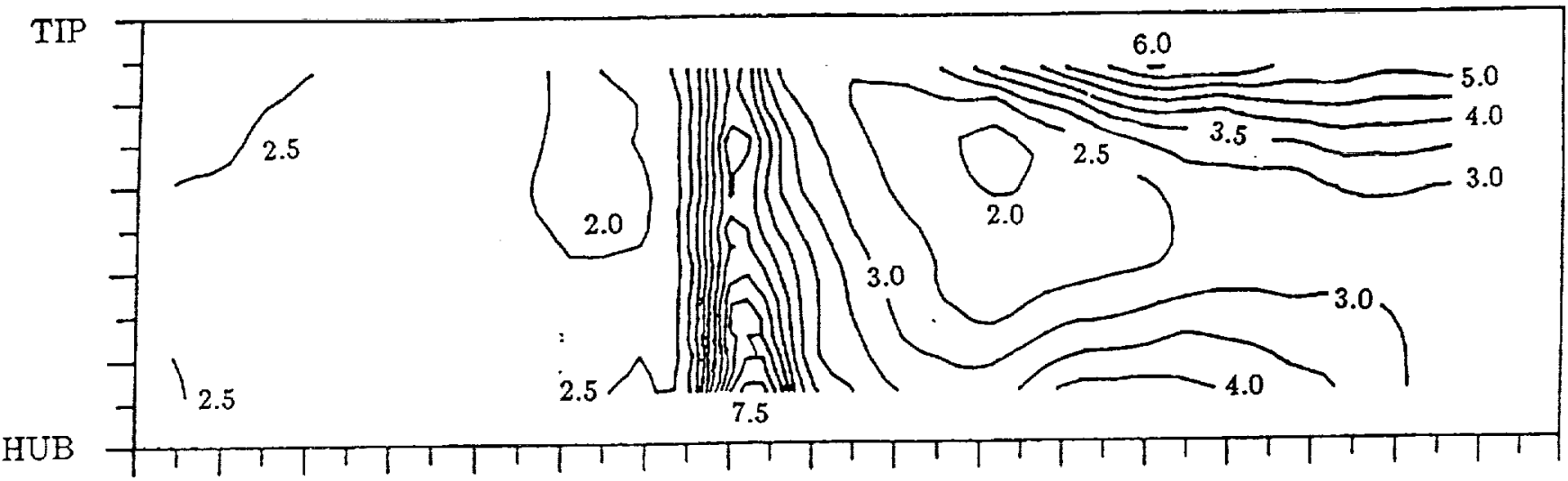

a) Data of Blair, $R e=2.37 \times 10^{5}$, Design Flow Angles.

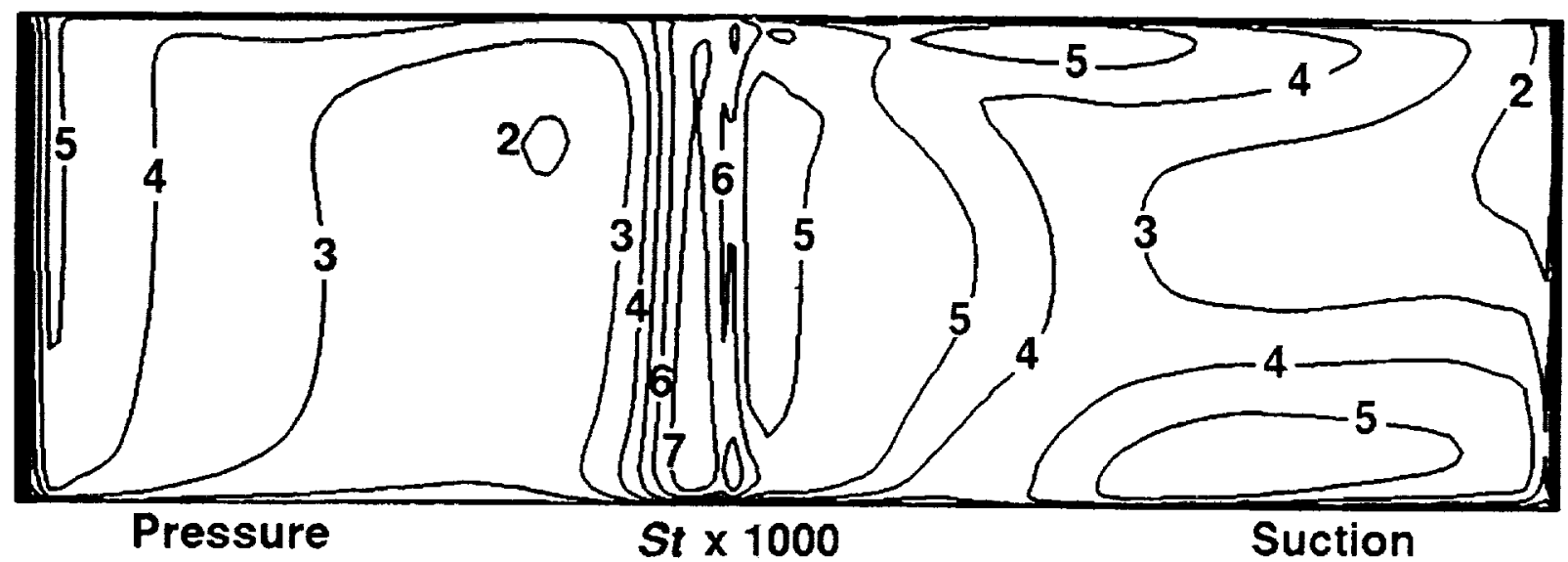

b) Prediction, $1 \%$ Clearance.

Figure 11. Comparison of Predicted and Measured Rotor Surface Heat Transfer.

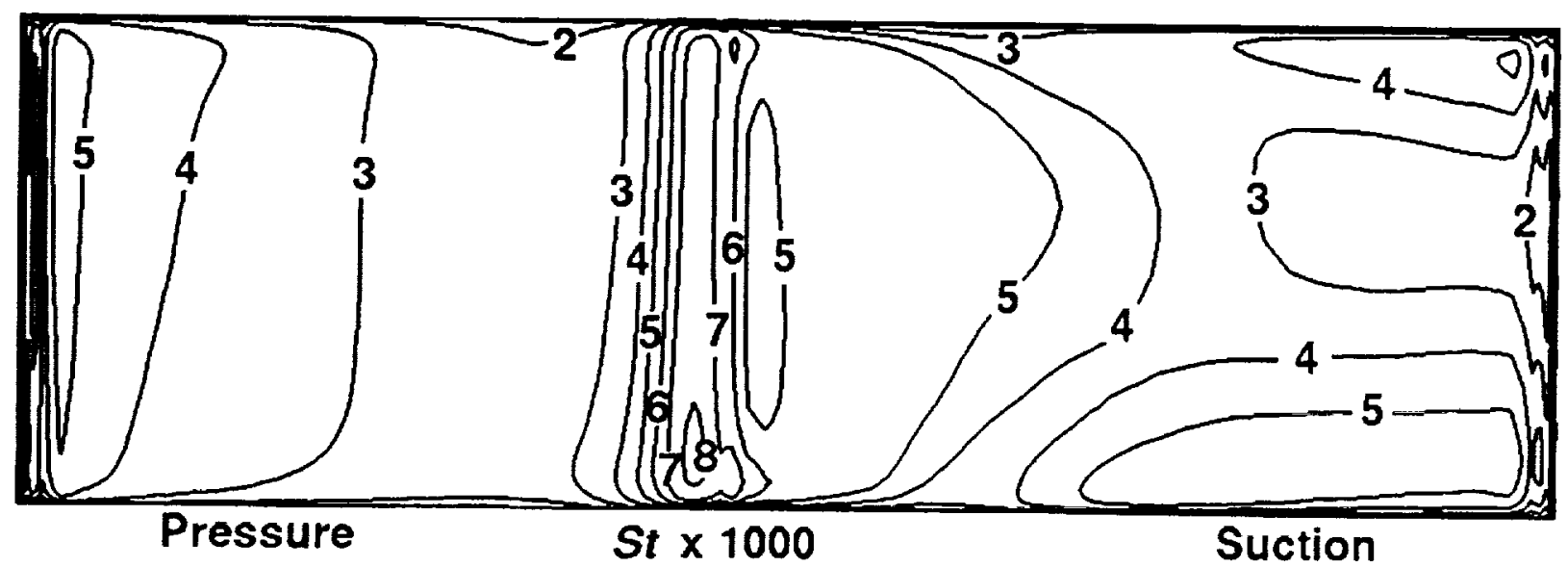

Figure 12. Calculated Heat Transfer for Blair's Rotor, Zero Clearance, Rotating Shroud. 
Publlc reporting burden for this collection of information is estimated to average 1 hour per response, including the time for reviewing instructions, searching existing data sources, gathering and maintaining the data needed, and completing and reviewing the collection of information. Send comments regarding this burden estimate or any other aspect of this collection of information, including suggestions for reducing this burden, to Washington Headquarters Services, Directorate for information Operations and Reports, 1215 Jefl

\begin{tabular}{l|l|l} 
Davis Highway, SU. REPORT TYPE AND DATES COVERED \\
\hline 1. AGENCY USE ONLY (Leave blank) & 2. REPORT DATE & 3. RE
\end{tabular}

\begin{tabular}{|l|l|l}
\hline 1. AGENCY USE ONLY (Leave blank) & $\begin{array}{c}\text { 2. REPORT DATE } \\
\text { July } 1992\end{array}$ & $\begin{array}{r}\text { 3. REPORT TYPE AND DATES COVERED } \\
\text { Technical Memorandum }\end{array}$ \\
\hline
\end{tabular}

\section{TIRE AND SUBTILE}

Three-Dimensional Navier-Stokes Heat Transfer Predictions for Turbine Blade Rows

\section{AUTHOR(S)}

Robert J. Boyle and Paul W. Giel

\section{PERFORMING ORGANIZATION NAME(S) AND ADDRESS(ES)}

National Aeronautics and Space Administration

Lewis Research Center

Cleveland, Ohio 44135-3191

9. SPONSORING/MONITORING AGENCY NAMES(S) AND ADDRESS(ES)

National Aeronautics and Space Administration

Washington, D.C. 20546-0001

\section{FUNDING NUMBERS}

WU-505-62-52

8. PERFORMING ORGANIZATION REPORT NUMBER

E-7230

10. SPONSORINGMONTTORING AGENCY REPORT NUMBER

NASA TM- 105800

AIAA-92-3068

\section{SUPPLEMENTARY NOTES}

Prepared for the 28th Joint Propulsion Conference and Exhibit cosponsored by the AIAA, SAE, ASME, and ASEE, Nashville, Tennessee, July 6-8, 1992. Robert J. Boyle, NASA Lewis Research Center, Cleveland, Ohio. Paul W. Giel, Sverdrup Technology, Inc., Lewis Research Center Group, 2001 Aerospace Parkway, Brook Park, Ohio 44142 (work funded by NASA Contract NAS3-25266). Responsible person, Robert J. Boyle, (216) 433-5889.

12a. DISTRIBUTION/AVAILABILITY STATEMENT

12b. DISTRIBUTION CODE

Unclassified - Unlimited

Subject Category 34

13. ABSTAACT (Maximum 200 words)

Results are shown for a three-dimensional Navier-Stokes analysis of both the flow and the surface heat transfer for turbine applications. Heat transfer comparisons are made with the experimental shock-tunnel data of Dunn and Kim, and with the data of Blair for the rotor of the large scale rotating turbine. The analysis was done using the steady-state, threedimensional, thin-layer Navier-Stokes code developed by Chima, which uses a multistage Runge-Kutta scheme with implicit residual smoothing. An algebraic mixing length turbulence model is used to calculate turbulent eddy viscosity. The variation in heat transfer due to variations in grid parameters is examined. The effects of rotation, tip clearance, and inlet boundary layer thickness variation on the predicted blade and endwall heat transfer are examined.

\begin{tabular}{l}
\hline $\begin{array}{l}\text { 14. SUBJECT TERMS } \\
\text { Turbine; Heat transfer; Three-dimensional }\end{array}$ \\
$\begin{array}{l}\text { 17. SECURITY CLASSIFICATION } \\
\text { OF REPORT } \\
\text { Unclassified }\end{array}$ \\
$\begin{array}{c}\text { 18. SECURITY CLASSIFICATION } \\
\text { OF THIS PAGE } \\
\text { Unclassified }\end{array}$
\end{tabular}

19. SECURTY CLASSIFICATION OF ABSTRACT Unclassified
15. NUMBER OF PAGES 16

16. PRICE CODE A03

20. LIMITATION OF ABSTRACT 